\title{
Plagas de langosta y clima en la España del siglo XVIII
}

\author{
Armando Alberola Romá* \\ UNIVERSIDAD DE ALICANTE (ESPAÑA)
}

Durante la Edad Moderna el campo español sufrió el ataque de numerosas plagas de langosta. En este artículo se estudian las correspondientes al siglo XVIII prestando especial atención al avance del conocimiento que se tenía en la época de la morfología y comportamiento del insecto, se analiza la relación entre clima y aparición de las plagas así como las consecuencias dejadas por éstas y los medios empleados para combatirlas.

(España, siglo XvııI, entomología, langosta, plaga, clima, desastre)

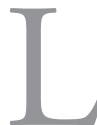

a beligerante convivencia del campesino con diferentes riesgos que pueden dar al traste con su trabajo y provocar la ruina en sus débiles economías familiares es una realidad milenaria. La meteorología, caprichosa e inclemente en demasiadas ocasiones, constituye uno de los más serios condicionantes de las cosechas. Una sequía persistente, una helada fuera de temporada, las tormentas veraniegas acompańadas de granizo o las temidas precipitaciones de alta intensidad horaria tan características del otońo y la primavera españolas constituyen riesgos de carácter físico, con origen climático o meteorológico, de consecuencias las más de las veces desastrosas. Pero a ellos se añade otro de tenor biológico cuyos efec-

* armando.alberola@ua.es Este artículo forma parte de los resultados del proyecto de investigación Riesgo y desastre natural en la España del siglo XVIII. Episodios meteorológicos extremos y sus efectos a través de la documentación oficial, la religiosidad popular y la reflexión cientifica (HAR2009-11928), financiado por el Ministerio de Ciencia e Innovación del Gobierno de España. 
tos llegan a superar, con creces, los dejados por los anteriores. Me estoy refiriendo a las plagas, en este caso de langosta, de efectos devastadores sobre campos y sembrados y, por ello, causantes de honda preocupación entre los campesinos. ${ }^{1}$

En trabajos anteriores efectué una primera aproximación a los efectos que dejó en los campos valencianos la terrible plaga de langosta que, entre 1754 y 1758 , azotó buena parte del territorio español. ${ }^{2}$ En ambos quedaba abierta la posibilidad de profundizar en esta línea investigadora pues el tema ofrece grandes posibilidades; no en balde al estudio de la evolución histórica del conocimiento de los aspectos meramente entomológicos se une el de otros enormemente sensibles en una sociedad de Antiguo Régimen como, por ejemplo, los de carácter económico y religioso-popular, sin olvidar la estrecha vinculación que una catástrofe de estas características tiene con la política, la sanidad o la técnica.

En esta contribución pretendo ofrecer un primer ensayo aproximativo a la incidencia que las condiciones medioambientales ejercieron en el desarrollo de las plagas de langosta que afectaron a ciertas partes del territorio español durante el siglo XVIII. A día de hoy disponemos de información que nos permite conocer con cierta seguridad el comportamiento del clima en Espańa durante el siglo XVIII. Abundantes datos al respecto los podemos hallar, entre otras fuentes, en los informes oficiales elaborados tras producirse diferentes calamidades - periodos prolongados de sequía, precipitaciones extraordinarias, inundaciones, frío y calor extremados-, en las solicitudes para llevar a cabo rogativas así como en la correspondencia mantenida por relevantes personalidades del Setecientos espańol.

\footnotetext{
${ }^{1}$ Sobre el concepto de riesgo véanse los trabajos de Francisco Calvo García-Tornel, El riesgo. Un intento de valoración geográfica, Murcia, Academia Alfonso X "el Sabio", 1982; "Le risque comme paradoxe et comme défi", en Gérard Chastagnaret, Les sociétés méditerranéennes face au risque. Disciplines, temps, espaces, El Cairo, Institut Français d'Archéologie Orientale, 2008, 165-178.

${ }^{2}$ Armando Alberola Romá, Catástrofe, economía y acción política en la Valencia del siglo XVIII, Valencia, ediciones Alfonso el Magnánimo, 1999, 207-235; "Procesiones, rogativas, conjuros y exorcismos. El campo valenciano ante la plaga de langosta de 1756", Revista de Historia Moderna, núm. 21, Universidad de Alicante, 2003, 383-410.
} 


\section{El TEMOR ATÁVICO A LA LANGOSTA}

La langosta, ese insecto ortóptero de la familia locustidae que, aunque de natural solitario, es capaz de convertirse en gregario a poco que medien las condiciones medioambientales adecuadas, siempre ha despertado un miedo irrefrenable en las sociedades agrícolas que sabían de sus cualidades polífagas y de su capacidad para acabar con todo tipo de vegetal que se pusiera a su alcance. Pasajes bíblicos, ${ }^{3}$ como el referido a la plaga que Yahvé envió a los egipcios para castigarlos o el que describe el tétrico protagonismo que, llegado el juicio final, adquirirán langostas transmutadas en escorpiones tras escucharse la trompeta del quinto ángel contribuyeron, junto con otros testimonios, a alimentar ese terror aludido al asociar las gentes su irrupción sobre los campos al deseo divino de corregir con extrema dureza las conductas de los hombres.

Pese a que desde la Antigüedad son conocidos los embates de este voraz insecto, sus características entomológicas y su ciclo biológico no fueron científicamente determinados con exactitud hasta finales del primer cuarto del siglo $\mathrm{xx} ;{ }^{4}$ por ello, y aunque durante la centuria de las Luces la pujanza de las Ciencias Naturales y la difusión del sistema clasificatorio de Linneo provocaron una mejora sustancial de las descripciones respecto de siglos pasados, no resultaba fácil discernir la especie responsable de las plagas.

En España hay constancia, desde épocas remotas, de los ataques perpetrados por la langosta, así como de sus consecuencias. ${ }^{5}$ Documentar los correspondientes a la Antigüedad y alta Edad Media ofrece cierta dificultad, pero a partir del siglo xv los archivos comienzan a ofrecer información, no todo lo abundante que el inves-

${ }^{3}$ Éxodo, 10, 1-20; Apocalipsis, 9, pp. 3-10.

${ }^{4}$ Boris P. Uvarov, Locusts and grasshoppers, Londres, The Imperial Bureau of Entomology, 1928; asimismo "Ecological studies of the Moroccan locust in Western Anatolia", Bulletin of Entomological Research, xxIII, 2, 1932, 273-287; "Ecology of the Moroccan locust in Iraq and Syria and the prevention of its outbreaks", Bulletin of Entomological Research, XXIV, 1, 1934, pp. 407-418.

${ }^{5}$ Miquel Barceló, "Les plagues de llagost a la Carpetània, 578-649...”, en Estudis d'Història Agraria, núm. 1, Barcelona, 1978, 67-84. 
tigador desea aunque sí reveladora ${ }^{6}$ que, para los siglos modernos, se incrementa de manera significativa tanto en cantidad como en calidad. El término langosta (locusta) era conocido en España desde el siglo XIII y, a partir del XVI, su definición encuentra acomodo en obras de referencia tales como el Tesoro de la Lengua Castellana o Española de Sebastián de Covarrubias o, más tardíamente, el Diccionario de Autoridades. Son definiciones de tenor descriptivo en las que se pone de manifiesto, sobre todo, el carácter dañino del insecto -"animalejo infecto y por mal nuestro conocido según el daño que hace en los frutos de la tierra" - así como el temor que su aparición causaba al ser tenido como "plaga y açote de Dios por los pecados de los hombres". ${ }^{7}$ Los comentarios dejados por diferentes tratadistas españoles durante los siglos XVI y XVII no permiten la plena identificación de la especie de la que hablan cuando se refieren genéricamente a la langosta; ${ }^{8}$ de ahí las dudas que se plantearon acerca de si las plagas se gestaban en el propio territorio peninsular o procedían del norte de África. Hasta hoy, y tras los estudios de José del Cañizo, está demostrado el carácter endémico de la Dociostarus maroccanus Thunberg (langosta mediterránea o marroquí) en algunas zonas de

${ }^{6}$ Rafael Vázquez Lesmes y Cándido Santiago Vázquez, Las plagas de langosta en Córdoba, Córdoba, Cajasur, 1993, 61; Julián Montemayor, "Les invasions de sauterelles dans l'Espagne intérieure", en Bartolomé Bennassar, ed., Les catastrophes naturelles dans l'Europe médievale et moderne, Toulouse, Presses Universitaires du Mirail, 1996, 262. Para el periodo medieval véase, entre otros, Juan Torres Fontes, "Los enemigos del hombre", Murgetana, LXI, 1981, fundamentalmente pp. 146-149; Juan Abellán Pérez, "Las plagas de langosta en el valle del Segura durante la primera mitad del siglo xv", Anales de la Universidad de Murcia, vol. 38, núm. 3, 1981, 81-94; Ma C. García Herrero y Ma J. Torreblanca Gaspar, "San Miguel y la plaga de langosta (Claves para la interpretación del voto taustano de 1421)", Aragón en la Edad Media, X-XI. Homenaje a la profesora Ma Luisa Ledesma Rubio, Universidad de Zaragoza, 1993, 281-305; Agustín Rubio Vela, "Presencia de la langosta. Plagas en la Valencia Bajomedieval", Saitabi, núm. 47, Valencia, 1997, 269-288.

${ }^{7}$ Alfredo Alvar Ezquerra, “Castilla 1590: tres historias ejemplares”, Studia Historica. Historia Moderna, núm. 17, Salamanca, 1997, 121-143.

${ }^{8}$ Abundante información sobre el tema, con notable aparato gráfico, se puede encontrar en Xavier Sistach, Bandas, enjambres y devastación. Las plagas de langosta a través del la historia; Almuzara, 2007. Véase igualmente Agustín Salido y Estrada, La langosta. Compendio de todo cuanto más notable se ha escrito sobre la plaga, naturaleza, vida e instintos de este insecto..., Madrid, Imprenta, Fundición y Estereotipia de don Juan Aguada, $1874,289-316$ y $319-334$. 


\section{Figura 1. Zonas permanentes de Langosta en España}

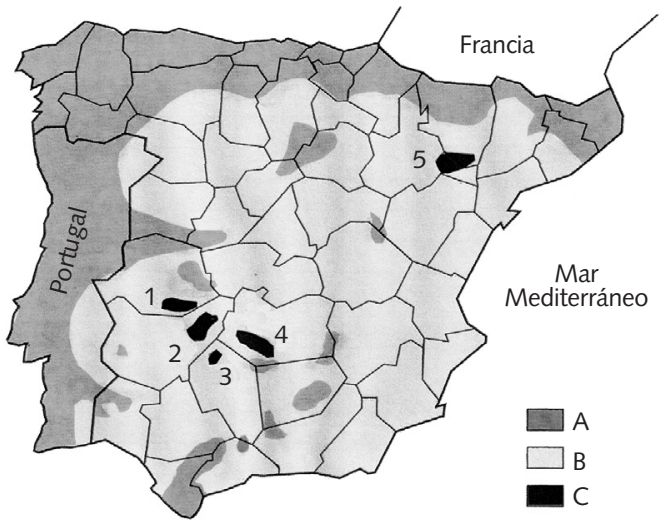

Claves: 1= Trujillo y Llanos de Cáceres. 2 = La Serena (Badajoz). 3= Los Pedroches (Córdoba). $4=$ Valle de Alcudia (Ciudad Real). 5= Los Monegros (Huesca y Zaragoza). A= región pirenaico-atlántica, de clima húmedo, y zonas interiores de máximas lluvias anuales. B=región seca de la Península Ibérica, cuyo límite señala el área de invasión, potencial, de las plagas de Dociostarus maroccanus Thunberg. C= Zonas permanentes o de reserva (Apud. José del Cañizo, "La langosta y el clima", 1942. Elaboración: C. Alberola Die).

\section{Espańa. ${ }^{9}$ Este autor establece la existencia de cinco áreas de reserva o} focos gregarígenos, perfectamente localizados geográficamente y caracterizados por unas condiciones medioambientales concretas que permitían a la langosta el paso de la fase solitaria a la gregaria bajo determinadas circunstancias climatológicas. ${ }^{10}$ Esas áreas de reserva,

${ }^{9}$ También resulta endémica de Espańa y susceptible de convertirse en plaga la Calliptamus italicus, localizada al oeste de las tierras manchegas en algunos pueblos de Albacete; cfr. en Antonio Buj Buj, "Control de las plagas de langosta y modernización agrícola en la Espańa de la segunda mitad del siglo xIx", en Geocrítica. Cuadernos Críticos de Geografía Humana, núm. 95, Barcelona, julio, 1992. Trabajo consultable igualmente en Scripta Vetera. Edición electrónica de trabajos publicados sobre Geografia y Ciencias Sociales, www. ub.es/geocrit/sv-59.htm. A. Arias Giralda, et al., La langosta mediterránea. Dociostarus maroccanus (Thunberg), Madrid, Ministerio de Agricultura, Pesca y Alimentación, 1994.

${ }^{10}$ José del Cañizo Gómez, "La langosta y el clima”, Boletín de Patología Vegetal y Entomología Agrícola, XI, Madrid, 1942, 179-200; José del Cañizo y V. Moreno, "Ideas actuales sobre las plagas de langosta”, Boletín de Patología Vegetal y Entomología Agrícola, Ix, Madrid, 1940, 107-136; Miguel Benlloch y José del Cañizo, "Observaciones biológicas sobre la langosta común (Dociostarus maroccanus Thunberg.), recogidas en los años 1940 y 1941", Boletín de Patología Vegetal y Entomología Agrícola, x, Madrid, 1941, 110-124; Miguel Benlloch, "In- 
tal y como se aprecia en la figura 1, se encuentran en las comarcas extremeñas de La Serena (Badajoz) y Trujillo (Cáceres), el Valle de Alcudia (Ciudad Real), el norte de la provincia de Córdoba (Los Pedroches) y, mucho más al noreste, Los Monegros (Huesca y Zaragoza). Todas ellas se encuentran en la porción árida peninsular y tienen unas características similares desde el punto de vista orográfico, climático y edafológico: relieve suavemente ondulado y con pendientes de no más de 12 por ciento; régimen pluviométrico muy irregular, con una notable oscilación interanual, pero siempre con precipitaciones inferiores a los $600 \mathrm{~mm} / \mathrm{anno}$; altas temperaturas en verano y suaves en invierno que no descienden de los $-5^{\circ} \mathrm{C}$, una humedad relativa media anual no más allá de 60 por ciento y un paisaje árido dominado por las gramíneas, el encinar degradado o los suelos incultos y abandonados.

\section{LA EVOLUCIÓN DEL CONOCIMIENTO DE LA LANGOSTA EN LA ESPAÑA MODERNA: DE LOS TRATADISTAS A LOS NATURALISTAS}

Durante la Edad Moderna la península Ibérica padeció abundantes incursiones de langosta que, combinadas con circunstancias meteorológicas especialmente adversas, redujeron sobremanera los rendimientos agrícolas provocando no pocas crisis de subsistencia con su corolario de hambre, enfermedad y muerte. Para los siglos XVI y XVII comenzamos a disponer de información precisa sobre el impacto causado por sucesivas plagas gracias al creciente número de monografías aparecidas en los últimos años que afrontan su estudio desde todos los enfoques posibles. ${ }^{11}$

fluencia de la humedad y la temperatura sobre la vitalidad y desarrollo de los huevos de langosta”, Boletín de Patología Vegetal y Entomología Agrícola, x, Madrid, 1947, 271-274.

${ }^{11} \mathrm{Al}$ respecto, y sin ánimo de ser exhaustivo, véase J. Meseguer Fernández, "Plaga de langosta en el marquesado de Villena y Castilla la Nueva, el año 1549”, Al-Basit, núm. 6, Albacete, 1979, 61-69; Ricardo Izquierdo Benito, "Las plagas de langosta en Toledo y la región manchega durante el siglo Xvı", en Anales Toledanos, Toledo, 1985, 47-143. Pere Catalá i Roca, La plaga de llagosta a Catalunya, 1686-1688, Barcelona, R. Dalmau editor, 1987; Rafael Marín López, "Noticias de una plaga de langosta en Granada en 1670 1671”, Actas del VII Congreso de Profesores-Investigadores. Hespérides, Motril, 1988, $245-$ 247; Ángel Aponte Marín, “Conjuros y rogativas contra las plagas de langosta en Jaén 
En la centuria ilustrada, la experiencia derivada de la aplicación de disposiciones legales dictadas a lo largo de los siglos para hacer frente a la desigual lucha contra el insecto, junto a los avances experimentados por las ciencias naturales, permitió identificar cada vez mejor a los causantes del tremendo desasosiego que embargaba a los campesinos tan pronto irrumpían entre sus sembrados las nubes de langosta. En este sentido, las aportaciones realizadas desde mediados de siglo por el naturalista Guillermo Bowles, irlandés al servicio de la monarquía borbónica, y por el jurista y botánico ilustrado aragonés Ignacio de Asso contribuyeron al mejor conocimiento del problema; sobre todo las del primero. Éste dedicó en su conocida Introducción a la Historia Natural y a la geografía fisica de España un amplio capítulo a la "langosta que desoló varias provincias de España" a mediados de la centuria ${ }^{12}$ en el que, aparte de describir la for-

(1670-1672)", en Carlos Álvarez Santaló y otros, coords., La religiosidad popular. II: Vida y muerte: la imaginación religiosa, Barcelona, 1989, 554-562; Adela Tarifa Fernández, Manuel Morales Romero y Enrique García García, "La ciudad de Úbeda a principios del siglo XviII: la plaga de langosta de 1709", Actas del X Congreso de Profesores-Investigadores. Hespérides, Sanlúcar de Barrameda, 1991, 299-308; Juan Antonio López Cordero y Ángel Aponte Marín, Un terror sobre Jaén: las plagas de langosta (siglos XVI-XIX), Jaén, 1993; José Rodríguez Molina, "Los insecticidas en la etapa pre-científica”, Boletín del Instituto de Estudios Giennenses, núm. 153, xL, 1994, 685-743; Milagros León Valdés, "Una simiente devastadora del agro antequerano: la plaga de langosta de 1620", Revista de Historia Moderna, núm. 23, Alicante, 2005, 285-306 (número monográfico dedicado a Agricultura, riesgos naturales y crisis en la España moderna); Adela Tarifa Fernández y Antonio Linaje Conde, "Úbeda, 1680-1713. Cambio dinástico y coyuntura económica"; Homenaje a don Antonio Dominguez Ortiz, vol. II, Granada, 2008, 757-770. En 2008 defendió en la Universidad Nacional de Educación a Distancia (UNED) Juan Cosme Sanz Larroca su Tesis Doctoral titulada Las respuestas religiosas ante las plagas del campo en la España del siglo XVIII; trabajo que permanece inédito en el momento de redactar estas líneas.

${ }^{12}$ De esta obra hubo dos ediciones; la primera se llevó a cabo en Madrid, en la imprenta de D. Francisco Manuel de Mena, en 1775, encontrándose las referencias a la langosta en las páginas 239-260; la segunda, corregida y con una introducción y cartas del diplomático José Nicolás de Azara, se imprimió en Madrid, en la Imprenta Real, en el año 1782, 257-279 (cito por esta segunda edición). En el primer cuarto del siglo XIX apareció este capítulo, en tirada aparte y acompañado de la Instrucción del Consejo de Castilla de 1755, bajo el título Historia natural de la langosta en España y modo de destruirla, por don Guillermo Bowles [...], Madrid, Imprenta de D. M. de Burgos, 1825, 40 páginas. En una breve nota final se justificaba la repetición, atendiendo a lo mucho de utilidad, ciencia natural y apreciable erudición que contiene dicho tratado, como lo acredita bien la particular estimación que se ha merecido en las cortes de Europa, y singularmente en Francia, donde los sabios autores [...] le tradujeron en aquel idioma. 
mación y los efectos de la plaga que azotó el país entre 1754 y 1758 , dejó anotadas las características del insecto y algunas recomendaciones para erradicar el mal.

Ignacio de Asso, por su parte, editaba en Holanda diez años más tarde, una suerte de compendio de lo publicado en Europa -también en Espańa, durante los siglos XVI y xvII- en el que reflexionaba sobre las causas que propiciaban la aparición de las bandadas del nocivo insecto y enumeraba los diferentes medios conocidos hasta la fecha para liquidarlas. ${ }^{13}$ Sorprendentemente, afirmaba desconocer el contenido de la Instrucción que el Consejo de Castilla emitió en el año 1755 con el objetivo de aniquilar la langosta en sus diferentes esta$\operatorname{dos}^{14} y$, ello no obstante, daba por buenos los comentarios que respecto de ésta decía haber escuchado, escribiendo textualmente que tal disposición legal "en sentir de muchos desempeña el argumento completamente". La verdad es que la ausencia de este referente imprescindible en la España de mediados del siglo xviı mueve a la perplejidad, sobre todo teniendo en cuenta la formación del aragonés, y dejaba un tanto devaluada la exhibición erudita de que hacía gala. ${ }^{15}$

Tanto Bowles como Asso vinculan la aparición de la plaga a las condiciones medioambientales, pero mientras que el primero da por sentado el "indigenismo" de la langosta y la sitúa permanentemente en zonas muy similares a las establecidas por los científicos contemporáneos, el segundo se inclina por el carácter foráneo e invasor de ésta al igual que postulaba Bartolomé Ximénez Patón un

${ }^{13}$ Ignacio Asso y del Río, Discurso sobre la langosta y medios de exterminarla. Por don-, Cónsul General de S. M. en Holanda, Sommer, Ámsterdam, MDcclxxxv.

${ }^{14}$ Instrucción formada sobre la experiencia y práctica de varios años para conocer y extinguir la langosta en su tres estados de ovación, feto o mosquito y adulta; con el modo de repartir y prorratear los gastos que se hicieren en este trabajo, aprobada por el Consejo el año 1755; en Novisima Recopilación, Reglas para la extinción de la langosta en sus tres estados; $y$ modo de repartir los gastos que se hicieren en este trabajo, Libro vII, Título XXXI, ley VII, aunque las leyes Ix y x complementan lo dispuesto en la anterior.

${ }^{15}$ Asso refiere en su Discurso infinidad de Tratados, tanto españoles como europeos publicados entre los siglos XVI y XVIII, que tratan la cuestión y proponen diferentes medios para combatir con eficacia las plagas de langosta. De ahí lo inexplicable de la situación; máxime si consideramos la estrecha relación que, en lo político, mantenía con los poderes centrales desde el desempeño de sus diferentes responsabilidades consulares en Europa. 
siglo atrás. ${ }^{16}$ Hay que decir que hasta la edición de la obra de Guillermo Bowles, el saber acumulado en Espańa sobre la langosta descansaba en los diferentes tratados aparecidos durante el siglo XVII. Algunos provenían de meras traducciones de lo que Plinio dejó anotado en su Historia Natural, como el publicado por Jerónimo de la Huerta en 1627. Otros, como el de Juan de Quiñones, ofrecían una notable erudición aunque escasa aportación personal pues este autor sólo utilizó textos y no llevó a cabo ningún trabajo de campo. En esta obra, por tanto, no se encuentran novedades, aunque Quiñones manifiesta un evidente interés porque su Tratado alcanzara la máxima difusión al considerar importante que el común conociera toda una serie de métodos de combate que se aplicarían contra la langosta en estado gregario, a la vez que elucubraba acerca de las causas coadyuvantes a su génesis. ${ }^{17}$

Las ideas contenidas en estos tratados mantuvieron su vigencia, sin evolucionar lo más mínimo, hasta el último tercio del siglo XviII en que apareció la Introducción a la Historia Natural de Guillermo Bowles. Éste no abrigaba dudas respecto del carácter endémico de la langosta, afirmando textualmente que ésta: "Es indígena de España, porque la que aquí se ve es de diferente especie de la que hay en el Norte y en Levante como se puede ver comparándola con la que se conserva de aquellos países en los Gabinetes de Historia Natural". ${ }^{18}$

Asimismo reconocía la influencia del clima para la "avivación", y por ello atribuía al insecto la cualidad de comportarse como un "termómetro viviente, que indica el calor respectivo de cada parage donde se halla", a la vez que establecía las áreas geográficas del país en las que encontraba acomodo apelando para ello a la experiencia de siglos de padecimiento: "por las historias y por la tradición consta

${ }^{16}$ Bartolomé Ximénez Patón, Discurso de la langosta que en el tiempo presente aflige, y para el venidero amenaza, por D. -. Baeza, 1619.

${ }^{17}$ Juan Quińones, Tratado de las langostas muy utily necesario, en que se tratan cosas de provecho $i$ curiosidad para todos los que professan letras divinas i humanas i las mayores ciencias. Compuesto por el doctor - [...] En Madrid, por Luis Sánchez impresor del Rey nuestro Señor, ańo de MDCxx. Sobre este asunto véase Javier Peris Felipo: "Apuntes sobre la lucha contra la plaga de langosta en los escritos de los siglos modernos", en Tiempos Modernos. Revista Electrónica de Historia Moderna, núm. 17, 2008/2.

${ }^{18}$ Guillermo Bowles, Introducción a la Historia Natural..., 2a edición, pp. 277-278. 
que la aparición de la langosta es una peste que aflige las Provincias meridionales de Espańa desde tiempo inmemorial [...]; que existe siempre en las dehesas incultas de Extremadura de donde sale, de tiempo en tiempo, a devorar otros países" ${ }^{19}$

La gran aportación de Bowles consistió en establecer los diferentes estados por los que pasaba la langosta desde el momento en que la hembra era fecundada por el macho y procedía a depositar sus huevos. Esta operación la efectuaba, habitualmente en el mes de agosto, en terrenos incultos, ásperos y cálidos empleando para ello una especie de aguijón hueco muy agudo y duro que posee en su parte posterior y que le permite horadar la tierra y construir un nido cilíndrico en el que introduce entre treinta y cincuenta huevecillos que, en la siguiente primavera, propiciarán el nacimiento de una generación de langostas. A comienzos de mayo comenzaban a aparecer en los eriales de La Mancha -aunque según los lugares podían haber nacido ya en abril- los que Bowles denominaba langostillos, de color oscuro y del tamaño de mosquitos, que se agrupaban formando una especie de "torta negra de tres o quatro pies" que se desplazaba a saltos a ras de suelo devorando cuanto vegetal encontraba sin alejarse en demasía del lugar de nacimiento. ${ }^{20}$ En junio, alcanzado el tamańo de adulta, además de repetir el ciclo reproductivo, las langostas se agrupaban ya en colonias conformando "una nube que intercepta los rayos del sol”, prestas a iniciar sus terribles vuelos sobre los campos. Éstos son, ni más ni menos, los tres estados de canuto, saltón y voladora o adulta que, junto con una descripción muy detallada de su morfología, constituían una novedosa línea de trabajo que sería continuada y de la que conviene destacar el esbozo de las hoy denominadas fases solitaria y gregaria. Respecto del modo de hacerles frente, Bowles apostaba por la prevención y, en ese sentido, recomendaba la localización de los lugares de ovación con el fin de poder destruir el mal antes de su nacimiento, instando a intendentes y corregidores a que pusieran en marcha las acciones necesarias que permitieran "aniquilar esta horrible plaga en las dehesas de

\footnotetext{
${ }^{19}$ Ibidem.

${ }^{20}$ Ibidem, pp. 269-270.
} 
donde se origina [...], con lo que se conseguirá exterminarlas de raíz". No alude Bowles en ningún momento al contenido de la Instrucción del Consejo de Castilla relativa a la cuestión, vigente desde mediados de la década de los cincuenta del siglo, aunque ésta sí recoge lo que en esos momentos se sabía acerca de las fases y comportamiento de la langosta.

Y es que cuando el Consejo de Castilla publicó en 1755 su Instrucción para conocer y extinguir la langosta en sus tres estados, Bowles apenas llevaba tres en España. Había sido captado en 1752 en París por Antonio de Ulloa para que se trasladara a Espańa y pusiera al servicio de la monarquía borbónica de Fernando vi sus conocimientos de Historia Natural, Química, Metalurgia y Anatomía adquiridos en la capital francesa a partir de 1740. Faltaban por tanto, todavía, veinte años para que apareciera su conocida Introducción a la Historia Natural. De ahí que la Instrucción, prolija en su articulado, contenga junto con las imprescindibles referencias a las costumbres y comportamiento del insecto causante de tantas desgracias, las reglas para combatir las plagas de langosta, el modo de hacer frente económicamente a los gastos que ello comportaba y el papel que desempeñarían las autoridades. No insistiré en los contenidos de la Instrucción, pero conviene dejar claro que en su articulado hay disposiciones precisas para, una vez localizados los lugares de ovación, proceder a la destrucción de los canutos, empleando para ello diferentes medios. De igual modo, la Instrucción establecía la manera de hacer frente al siguiente estadio de desarrollo, el de feto o mosquito, en el que el insecto no podía alzar el vuelo aún y, llegado el caso y alcanzada la madurez, cómo combatir a la langosta adulta o saltadora. ${ }^{21}$

Los comentarios de Bowles fueron utilizados profusamente en España durante el último tercio del siglo xviII, bien reproduciéndolos de manera textual o recurriendo a la paráfrasis. Ello es observable, por ejemplo, en las páginas del Semanario de Agricultura y Artes dedicado a los Párrocos que, a comienzos del siglo xIX y a cuenta de un escrito del duque del Infantado referido a los sufrimientos que

${ }^{21}$ Estos aspectos ya los analicé en el ya citado trabajo "Procesiones, rogativas, conjuros y exorcismos...”. 
deparó una plaga de langosta en sus señoríos en 1799, reproducía en dos entregas sucesivas fragmentos del capítulo que el naturalista irlandés dedicó a la cuestión en su obra así como los remedios recomendados por la Instrucción del Consejo de Castilla. ${ }^{22}$ Ignacio de Asso también utiliza a Bowles en su Discurso, del mismo modo que, por ejemplo, Juan Antonio Zepeda, cura de Malpartida de Plasencia, en su Agricultura Metódica. El primero lo cita adecuadamente mientras que el segundo, pese a que parece conocer su obra, evita hacerlo recurriendo a la expresión eufemística "dicen algunos Escritores". ${ }^{23}$ La convocatoria de certámenes animando a investigar sobre la langosta y los problemas que ocasionaba por parte de algunas de las Sociedades Económicas de Amigos del País da una idea de la relevancia que se concedía al asunto.

A finales de la centuria ya se tenían claras algunas cosas, resultado de una observación atenta y sistemática de la realidad. Entre ellas que la abundancia de tierras yermas en las regiones meridionales y sur occidentales de la Península, unida a "la aridez del terreno, el temperamento cálido y la sequedad continuada” eran causas que podían "promover y aumentar la fecundidad de la langosta en la España meridional”. Y en esto coincidían Bowles y Asso, así como otros autores de menor enjundia pero que habían dedicado su tiempo a la observación y la reflexión. Precisamente una de las Memorias llegadas a la Sociedad Matritense en 1785 especulaba acerca de cómo podía favorecer o no la meteorología al desarrollo de la langosta, indicando textualmente que la plaga se adivina "Quando aviendo precedido ańos secos y muchos vientos cálidos se deja ver enorme cantidad de orugas, pulgón o rosquillas y langostas [...] Si se confirmara por otras experiencias y observaciones se podría adivinar la plaga de langosta dos años antes y estar preparados". ${ }^{24}$

22 Semanario de Agricultura y Artes dedicado a los párrocos, tomo viI, núm. 157, del jueves 2 de enero de 1800, 11-16; y núm. 158, del jueves 9 de enero de 1800, pp. 25-32.

${ }^{23}$ Juan Antonio Zepeda y Vivero, Agricultura metódica, acomodada a la práctica del país, con varias noticias acerca de la naturaleza, propagación y extinción de la langosta. Escrita por don-. Cura rector del lugar de Malpartida de Plasencia, Madrid, en la Oficina de don Benito Cano, año de MDCCXCI, especialmente pp. 158-170.

${ }^{24}$ La referencia la tomo de Rafael Vázquez Lesmes y Candido Santiago Álvarez, op. cit., p. 93. 
Esta preocupación por desentrańar los misterios de la Naturaleza alcanzaba a los que podríamos denominar ilustrados de "tercer nivel” o, como los llamaba Agustín Salido "insignes amigos de la agricultura y de la Humanidad" 25 que, pese a las muchas y variadas limitaciones a que debían hacer frente, pugnaban por ser útiles a la sociedad. Es el caso, entre otros, del ya aludido Juan Antonio Zepeda, cura de Malpartida de Plasencia (Cáceres), quien se lamentaba al concluir sus reflexiones sobre la langosta incluidas en su Agricultura metódica de no haber dispuesto de más medios -fundamentalmente bibliográficos- que enriquecieran su texto; que, entre otras cosas, deseaba "pudiera ser de utilidad en orden a fomentar la Agricultura y mejorar sus frutos". ${ }^{26}$ En abierta sintonía con otros escritos circulantes, ${ }^{27}$ anotaba que la experiencia y el estrecho contacto con el medio le había enseñando que la langosta se multiplicaba "naturalmente, más o menos, según los terrenos o climas, según las alteraciones de los tiempos", aunque añadía que también tenían que ver "los influxos de los astros". Observando el comportamiento de la meteorología durante los años 1780-1782, en la comarca donde profesaba su ministerio, dedujo la estrecha relación existente entre la mutación de solitaria a gregaria de la langosta y los periodos de sequedad o lluvia durante las primaveras y veranos, junto con el alargamiento de los fríos invernales -nevadas incluidas-más allá del mes de abril.

Climáticamente hablando, el continente europeo conoció en el siglo XVIII -sobre todo en su segunda mitad- el inicio del tránsito hacia una fase algo más cálida tras haber sufrido los peores momentos de la denominada Pequeńa Edad del Hielo (PEH). Durante este periodo, que se extendió desde mediados del siglo xv hasta bien entrado el siglo XIx, los climatólogos históricos indican que se padecieron fríos tan severos como los de la última glaciación. La España moderna, obviamente, conoció los efectos generales de la PEH y durante el siglo XVIII se dejó notar también esa recuperación térmica

${ }^{25}$ Agustín Salido y Estrada, op. cit., p. 8.

${ }^{26}$ Juan Antonio Zepeda y Vivero, op. cit., p. 170.

${ }^{27}$ Francisco Aguilar Piñal recoge en su catálogo de autores del siglo XvıII cerca de una treintena de impresos, de diferente índole, referidos a la langosta; véase Bibliografía de autores españoles del siglo XVIII, 10 vols., Madrid, CsIC, 1998-2001. 
aludida, aunque la amplia variabilidad climática de las centurias anteriores se mantuvo y, en ocasiones, se acentuó. Veamos de qué manera pudo influir ello en el desarrollo y proliferación de la langosta.

\section{Condiciones medioAmbientales Y LANGOSTA \\ EN LA ESPAÑA DEL XVIII}

A comienzos de la centuria ilustrada, coincidiendo con los duros combates de la Guerra de Sucesión a la corona española y con unos ańos especialmente severos en lo climático, la península Ibérica padeció una plaga general de langosta que motivó la publicación de una Real Provisión por parte de Felipe $\mathrm{V}$ a primeros de octubre de 1708 para hacer frente al problema. ${ }^{28}$ Hay pruebas fehacientes del dańo causado en tierras cordobesas y jiennenses ${ }^{29} \mathrm{y}$, en general, en toda Andalucía, así como en La Mancha ${ }^{30}$ y en el Levante peninsular donde, además, los ejércitos borbónicos proseguían la conquista del territorio a sangre y fuego. ${ }^{31}$ Díaz-Pintado hace ver que en tierras manchegas siempre había langosta, poca o mucha, y aunque entre 1706 y 1710 no llegara a sobrepasar los estrechos límites territoriales donde solía desarrollarse, en la primavera y comienzos del verano de esos años los voraces insectos acabaron con todos los frutos de La Solana y Daimiel. ${ }^{32}$ A escala general, el bienio 1708-1709 resultó dramático, al coincidir los desastres de la guerra con los meteorológicos y biológicos, dando lugar a una terrible crisis de subsistencia.

La sequía comenzaría a dejarse sentir a lo largo y ancho de la geografía peninsular a partir de 1711. Durante este año y el siguiente la

${ }^{28}$ Vicente Pérez Moreda, Las crisis de mortalidad en la España interior (siglos XVI-XIX), Madrid, Siglo XXI editores, 1980, 361, nota 308.

${ }^{29}$ Rafael Vázquez Lesmes y Candido Santiago Vázquez, op. cit., p. 70. A. Tarifa Fernández y A. Linaje Conde, op. cit., pp. 767-768; J. A. López Cordero y Á. Aponte Marín, op. cit., pp. 92-94.

${ }^{30}$ Ramón Cózar Gutiérrez, "La administración municipal y el control de las plagas de langosta en Albacete a principios del siglo xvin", Ensayos. Revista de la E.U. de Magisterio de Albacete, núm. 18, Albacete, 2003, 47-60.

${ }^{31}$ Archivo Histórico Nacional (AHN), Nobleza, Osuna, CT 142, D. 60 y D. 82

32 Juan Díaz-Pintado, "Climatología de La Mancha durante el siglo xvıII", en Cuadernos de Historia Moderna, núm. 12, Madrid, 1991, 144-145. 
sequedad fue extrema en la Meseta norte y, entre 1718 y 1724, la comarca de los Monegros - una de las zonas gregarígenas de langosta por excelencia- no conoció cosecha alguna. Un factor determinante para la irrupción de las plagas resulta ser una previa y persistente sequía de al menos cinco años combinada, eso sí, con lluvias primaverales abundantes. Quizá por ello, y durante la década de los veinte, la langosta volvió a aparecer en los lugares habituales. Así, la comarca septentrional cordobesa de Los Pedroches la padeció desde 1721 y hay constancia de su presencia, dos años más tarde, en algunas poblaciones manchegas ${ }^{33}$ así como en Jaén y Ciudad Real. ${ }^{34}$ A la Puebla de Montalbán (Toledo) llegarían las nubes de insectos en $1727,{ }^{35}$ causando notable sobresalto y preocupación. En tierras meridionales valencianas, donde se soportaba una prolongada sequía a tenor de la información que proporciona la correspondencia de diferentes personalidades del mundo de la cultura y de la política, hay constancia, en abril de 1727, de la alarma causada en las gobernaciones de Alicante y Alcoi tras contemplar la irrupción de langosta así como del envío de comisionados a Jumilla, Orihuela y Murcia para conocer los métodos que se empleaban para extinguirla. ${ }^{36} \mathrm{Del}$ 11 de septiembre de 1723 data precisamente la orden del Consejo de Castilla que, signada por Felipe v, proporcionaba instrucciones a las autoridades locales para organizar la extinción de la langosta cargando los gastos a los fondos de Propios de cada localidad. ${ }^{37}$

Pero fue la plaga de mediados del siglo Xvin la que mereció una especial atención por su dimensión y por las notables secuelas que dejó a su paso. Ya se ha comentado que Guillermo Bowles la aprovechó para dedicar un amplio apartado a la descripción morfológica y costumbres de este ortóptero en su Introducción a la Historia natural y que desde el punto de vista político-legal el Consejo de Castilla aprobó la famosa Instrucción de 1755 con el objetivo de regular el

${ }^{33}$ Es el caso de Membrilla, La Solana o Villarrobledo; cfr. en ibidem, p. 145. Para Villanueva de los Infantes (Ciudad Real), véase AHN, Consejos, legajo 35254, expediente 13.

${ }^{34}$ Juan Antonio López Cordero y Ángel Aponte Marín, op. cit., pp. 109-110.

${ }^{35}$ AHN, Consejos, leg. 35,134, exp. 3.

${ }^{36}$ Armando Alberola Romá, Catástrofe, economía..., pp. 209-210.

${ }^{37}$ Novisima Recopilación, Libro VII, Título XXXI, Ley vI. 
combate contra los "nocivos animales". Aunque, como también se ha dicho, no se trata de la primera de las disposiciones que al respecto podemos encontrar a lo largo de los siglos, sí es la que con más detalle describe los métodos que se emplearían contra el insecto en sus diferentes estados de desarrollo estableciendo, asimismo, el procedimiento económico al que debían sujetarse las diferentes autoridades para hacer frente a los gastos que su extinción generara. ${ }^{38}$

Los expertos convienen en que el paso de la fase solitaria a la gregaria en la langosta obedece a la conjunción de una serie de circunstancias, entre las que el clima desempeña un papel importante. Varios años de sequía continuada salpicados por precipitaciones primaverales de cierta entidad y con una última anualidad extremadamente seca garantizan la conformación de una plaga. ${ }^{39}$ También las lluvias tardoinvernales, coincidiendo con temperaturas no excesivamente bajas, pueden influir en el avivamiento y desarrollo de la langosta cuyos huevos, no olvidemos, se depositan a comienzos del verano anterior. El largo periodo de diapausia dura, por tanto, hasta la siguiente primavera ya que el frío del invierno no beneficia el desarrollo del embrión. Lluvias copiosas en enero o febrero acompañadas de temperaturas agradables pueden provocar, sin embargo, un avivamiento prematuro y la aparición de langostas, aunque sin muchas probabilidades de sobrevivir. Las circunstancias previas a la gran plaga de mediados de siglo vienen a coincidir, a grandes rasgos, con este esquema.

En 1748, la sequía "era general en todo el reino", según escribía desde Madrid el magistrado Blas Jover al ilustrado valenciano Gregorio Mayans, mientras le hacía patente su preocupación por los graves inconvenientes que podía provocar la conjunción de una adversa meteorología con la feroz langosta azotando los campos manchegos, castellanos y extremeños. ${ }^{40}$ La sequedad proseguiría implacable hasta

${ }^{38}$ Es por ello que el compilador decimonónico Agustín Salido la considera "base histórica de la legislación del ramo"; op. cit., p. 174.

39 José del Cañizo Gómez, "La langosta y el clima”, pp. 190-195.

${ }^{40}$ Todas las referencias a las oscilaciones climáticas que siguen se encuentran en $\mathrm{Ar}$ mando Alberola Romá, "No puedo sujetar la pluma de puro frío, porque son extremados los yelos. El clima en la España de los reinados de Felipe V y Fernando VI a través de la correspondencia de algunos ilustrados", en Investigaciones Geográficas, núm. 49, 2009, 65-88. 
bien entrada la quinta década del siglo, destruyendo cosechas, encareciendo el precio de los cereales, abocando al hambre y la pobreza a las clases populares y casi obligando a dejar en suspenso el suministro de agua potable, como estuvo a punto de suceder en la Corte.

La "gran esterilidad en los quatro reynos de Andalucía" se amplió a la totalidad del país al comenzar los ańos cincuenta, apenas interrumpida por tormentas ocasionales y pedriscos que refrescaban momentáneamente el ambiente. El invierno de 1750-1751 resultó frío y lluvioso en el interior y desconcertante en la costa, con anómalas y breves bonanzas térmicas. El verano de 1751 fue muy caluroso y sin gota de agua, y los pocos chaparrones del otońo apenas contribuyeron a "templar los calores" pero no salvaron las cosechas. Sequía constante, frío invernal, calor agobiante en verano y esporádicas -aunque las más de las veces impresionantes- precipitaciones otońales marcaron los años previos a la invasión por la langosta de la práctica totalidad de la geografía española. El literato Luis José Velázquez de Velasco, marqués de Valdeflores, en tránsito por tierras extremeñas en dirección a Andalucía recopilando materiales para escribir una Historia de España, se lamentaba durante la primavera y el verano de 1753 de la extrema sequía que se padecía en un "país que por su naturaleza es seco i cálido, [pero] lo es mucho más a causa de no haver llovido en el invierno"; rematando que "si en alguna tierra no se puede trabajar por el verano es en Extremadura". ${ }^{41}$

El invierno de 1753-1754 fue riguroso y con muchas lluvias, tanto en la costa mediterránea como en el interior de España. Llegado el mes de abril, las precipitaciones descargaron con profusión a lo largo y ancho del país, con excepción de "Aragón que no ha sido cosa, i especialmente en tierra de Huesca", según anotaba el bibliotecario real Manuel Martínez Pingarrón a Gregorio Mayans. Sequía continuada y lluvias primaverales dieron como resultado que, en las zonas permanentes, la langosta iniciara su transformación. A partir de este verano, y hasta el de 1758, la plaga se extendió inmisericorde.

${ }^{41}$ Biblioteca Nacional. Manuscrito 17,546, Epistolario Luis José Velázquez-Agustín Montiano; Velázquez a Montiano, Mérida, 22-6-1753; f. 66. 
Iniciada en Extremadura en 1754, se desplazó con rapidez hacia Portugal y La Mancha, alcanzando posteriormente Andalucía, Murcia y el antiguo reino de Valencia "causando todos los horrores del hambre y la miseria y llevando consigo el terror y la desolación". ${ }^{42}$ En tierras albaceteñas y valencianas la langosta irrumpió en el verano de 1756 y, moviéndose en todas direcciones, provocó el miedo y la inmediata alerta en las poblaciones, persuadidas de que se estaba fraguando una catástrofe agrícola. ${ }^{43}$ Díaz-Pintado destaca el castigo sufrido por los campesinos de los Campos de Montiel y de Calatrava, mientras que de su paso por Andalucía conocemos con detalle las secuelas dejadas en Córdoba gracias a la monografía de Vázques Lesmes y Santiago Álvarez; también disponemos de noticias de lo acontecido en los territorios del conde de Bornos o de los marqueses de Torrelaguna ${ }^{44} \mathrm{y}$ en algunas poblaciones extremeńas como Valencia del Ventoso ${ }^{45}$ La magnitud del desastre ocasionado por la langosta en los campos espańoles, la relativa eficacia mostrada por las recomendaciones de la Instrucción y la ciega convicción de que la solución vendría de la mano de remedios de carácter espiritual, determinó que el rey Fernando VI decidiera, mediante Real Provisión fechada el 14 de octubre de 1756, que las reliquias del venerado San Gregorio Ostiense salieran de su santuario en tierras de Navarra y recorrieran buena parte de la geografía espańola. Ello no impidió, sin embargo, que la plaga causara grandes estragos hasta que se extinguió por sí sola. Procesiones, rogativas y cuantiosas cantidades de dinero invertidas -tanto en ceremonias piadosas como en jornales- dieron cumplido testimonio de este episodio, que no sería el último hasta que la centuria concluyera. La correspondencia a la que vengo haciendo alusión recoge abundantes noticias al respecto que reflejan la impotencia de pueblos, gobernantes

${ }^{42}$ Guillermo Bowles, op. cit., p. 258.

${ }^{43}$ María Belén Piqueras García, "Una amenaza para la agricultura de Almansa: las plagas de langosta (1756-1759), en Al-Basit, núm. 23, Albacete, 1988, 189-201. Armando Alberola Romá, "Procesiones, rogativas..."; en este trabajo se refleja con detalle lo que supuso la presencia de la plaga en todas las comarcas valencianas durante tres cosechas, obviamente perdidas.

${ }^{44}$ AHN, Nobleza, Bornos, C. 802, D. 17 y Torrelaguna, C. 244 , D. 5.

${ }^{45} \mathrm{AH}$, Consejos, leg. 27016, exp. 8. 
y, evidentemente santos y similares, para liquidar de manera definitiva el problema.

Las dos décadas postreras del XviII conocieron nuevos ataques de la langosta. Agustín Salido anota una plaga para Andalucía durante el año 1779 que Díaz-Pintado recoge igualmente para el Campo de Montiel, apunta Julián Montemayor que las operaciones contra la plaga supusieron a la ciudad de Toledo un desembolso superior a los 830,300 reales de vellón. ${ }^{46}$ Información más abundante, y en espera en algunos casos de ser estudiada con detalle, disponemos para los años $1782-1785$ y $1790-1791$.

El estío de 1781 trajo "ardientes calores", tras estar "sin lluvias durante muchos meses", y le siguieron "un otoño frío y húmedo" y "un invierno nebuloso", según escribió Joaquín de Villalba en su Epidemiología española. ${ }^{47}$ Esta caracterización es generalizable a toda esta década, pues a la implacable sequía presente a lo largo y ancho del territorio peninsular se añadió un incremento muy notable de la pluviosidad extraordinaria de consecuencias catastróficas. Esta seria perturbación atmosférica, claramente perceptible en la fachada mediterránea, dejaría sentir sus efectos hasta los albores del siglo XIX. Bien estudiada en la actualidad, se caracteriza por la coincidencia de episodios hidrometeorológicos extremos de carácter extraordinario; es decir, que la dura e intermitente sequía que se arrastraba desde mediados de siglo convivió con violentas y reiteradas precipitaciones que provocaron riadas e inundaciones, siendo asimismo habituales los inviernos rigurosos, los pedriscos y heladas y los veranos cortos y húmedos. ${ }^{48}$ En este contexto, la langosta se dejó notar en diferentes puntos de la geografía española. Así, en Orihuela -al sur de las tierras valencianas- el ayuntamiento hubo de tomar providencias para tratar de extinguirla en $1782 ;{ }^{49}$ del mismo modo que

\footnotetext{
${ }^{46}$ Agustín Salido y Estrada, op. cit., p. 176. Juan Díaz-Pintado, op. cit. J. Montemayor, op. cit., p. 266.

${ }^{47}$ Joaquín de Villalba, Epidemiología española o historia cronológica de las pestes, contagios, epidemias y epizootias que han acaecido en España..., vol. II, Madrid, 1803, 248.

${ }^{48}$ Armando Alberola Romá, Quan la pluja no sap ploure. Sequeres i riuades al Pais Valencià en l'edat moderna, Publicaciones de la Universidad de Valencia, Valencia, 2010, 180 y ss.

${ }^{49}$ AHN, Consejos, leg. 37,127.
} 
un año más tarde hubieron de hacer en Santa Catalina de Verjamuñoz (Toledo) o en Sos del Rey Católico, en la villa de Fons y en otras poblaciones del corregimiento de Barbastro tal y como refleja la abundante documentación conservada en la sección de Consejos del Archivo Histórico Nacional. De estos años datan las Memorias que se remitieron a la Sociedad Matritense de Amigos del País para participar en el certamen que, sobre la langosta y el modo de hacerle frente, convocó la institución. Ninguna resultó premiada, pero de la lectura de los fragmentos que de algunas de ellas se publicaron se desprende el conocimiento que, a esas alturas del siglo, se tenía de la especie y de la relación existente entre condiciones ambientales y los cambios que experimentaba. Así, se comienza a dar por sentado que las altas temperaturas y las sequías prolongadas eran causas que, combinadas entre sí, podían promover y aumentar la langosta hasta conducirla a la fase gregaria y provocar la consiguiente calamidad; por el contrario, lluvias abundantes en otońo y primavera contribuían a reducir la puesta impidiendo que el insecto superara la fase solitaria y minimizando, en consecuencia, el peligro. ${ }^{50}$ En esta línea, el anteriormente aludido cura de Malpartida de Plasencia deja constancia del resultado de sus observaciones durante los años 1781 y 1783 en los que, pese a haber langosta en el término, los dańos no fueron graves gracias a la acción previsora del corregidor que "procuró que se matase en la cuna y estrechó a las justicias de todo el partido para que lo hiciesen". ${ }^{51}$ Respecto de la relación entre meteorología y desarrollo de la langosta indicaba textualmente:

El año 80 fue seco y correspondería igual en el tiempo de la seminación; la Primavera de 81, aunque no fue húmeda, llovió a principios de abril lo bastante para que con el calor se vivificasen las semillas [...] Lo cierto es que un frío extraordinario en cualesquiera de los dos tiempos hubiera destruido casi toda la cría [...], y qué se yo si las lluvias de agosto, antes de que se sequen bien las paredes de las casitas, pudieran destruir muchas o atrasar la seminación [...] El Agosto

${ }^{50}$ Rafael Vázquez Lesmes y Candido Santiago Vázquez, op. cit., pp. 30-31.

${ }^{51}$ Juan Antonio Zepeda y Vivero, op. cit., p. 167. 
de 81 fue sereno, y aunque hubo gran matanza la compensó la seminación [...] Mas en abril de 82 hubo tal contratiempo de frío y nieve que podemos presumir heló la mayor parte de las crías; porque a la verdad no parecieron, y las pocas que se notaron fueron tardías, que se llegó la cosecha antes de que pudieran dañarnos. No tiene duda que en todo tiempo el calor del sol con mediana humedad las vivifica, como tengo experimentado [...]; en este tiempo cualesquier frío la dańará, porque no tiene aquella defensa que le previno la madre, y presumo que en todo tiempo el frío las destruye. ${ }^{52}$

Reflexiones todas ellas procedentes de la observación y que, como decía su autor, aspiraban a servir de ayuda a la hora de librar el desigual combate contra las plagas de langosta. A comienzos de la última década del siglo, los campos de buena parte del país volvieron a ser presa de los feroces ortópteros. Abundan las informaciones y providencias que, durante los ańos 1790 y 1791, circularon procedentes de poblaciones manchegas, extremeñas o cordobesas dando cuenta de la situación ${ }^{53} \mathrm{y}$, a buen seguro, estudios inmediatos contribuirán a ampliar los conocimientos de que, a día de hoy, disponemos. ${ }^{54}$

\section{CONSIDERACIÓN FINAL: ENTRE LOS REMEDIOS TERRENALES Y LOS ESPIRITUALES}

Las plagas de langosta constituyeron uno más de los problemas que la agricultura española hubo de resolver durante el siglo XviII.

52 Ibidem, pp. 168-169.

${ }^{53}$ En la ya aludida sección de Consejos del AHN se conserva la documentación relativa, entre otras, a las localidades toledanas de Carmena, Puebla de Montalbán, Talavera de la Reina, Urda y la propia ciudad de Toledo. De Ciudad Real hay datos correspondientes a Mestanza, Puertollano, Valdepeńas y Almodóvar del Campo. Para Córdoba contamos con los de Hinojosa del Duque y Torrefranca, y para tierras extremeñas hay referencias a Campanario, Castuera, Escorial y Villanueva de la Serena.

${ }^{54}$ Isabel Azcárate Luxán y Luis Maldonado Polo, "La plaga de la langosta y el tizón del trigo en la España ilustrada”, en Llull, vol. 15, 1992, 309-330. Oswaldo Brito González, "La langosta en Canarias durante el Antiguo Régimen", en Anuario de Estudios Atlánticos, núm. 35, 1989, 67-102. 
Cómo afrontar con garantías la lucha contra el insecto en su fase gregaria fue motivo de sucesivas disposiciones legales promulgadas durante la centuria de las Luces. La tantas veces mencionada Instrucción del Consejo de Castilla de $1755,{ }^{55}$ junto con sus adiciones y modificaciones de 1783 y 1785 , desgranaba una serie de recomendaciones y obligaciones que debían de tener en cuenta los responsables políticos de las localidades afectadas. De capital importancia, dado su carácter preventivo, eran las acciones a emprender para localizar los parajes de puesta durante el otońo e invierno con el fin de destruir los canutos. Asimismo, el empleo de variado utillaje -arados, azadas, rastrillos, palas o barras de madera y hierro- combinado con la presencia de cerdos, gallinas o pollos para liquidarlos ocupa parte del articulado que, además, incluye los mecanismos para hacer frente a la langosta en sus fases de mosquito y saltadora. El pisoteo por parte del ganado, la acción de los vecinos organizados en cuadrillas que golpean las nubes de mosquitos con toda suerte de artefactos, el uso de bueytrones o grandes cazamariposas para capturar a la langosta adulta al vuelo, su incineración y enterramiento para evitar problemas sanitarios, las gratificaciones a quienes prestaban sus servicios, etcétera, son aspectos tratados con sumo detalle, junto con las pautas establecidas para hacer frente a los elevados gastos que todo ello comportaba. Porque, en ocasiones, aunque las plagas no llegaran a afectar en demasía las cosechas, sí lo hacían con las arcas municipales que debían desembolsar fuertes sumas de dinero en aplicación de lo establecido en la Instrucción como, por ejemplo, sucedió en Jerez de la Frontera en diferentes ocasiones. ${ }^{56}$

Junto con estas medidas de carácter técnico-legal consideradas -todo hay que decirlo- poco efectivas, la sociedad ponía en marcha de manera paralela otros mecanismos en los que miedo, superstición o religiosidad popular estaban bien presentes. Asumido que el combate que se libraría contra el nocivo animal resultaba desigual y condenado al fracaso, y que la plaga no era ni más ni menos que un

${ }^{55}$ Véase nota 14.

${ }^{56}$ Jesús Manuel González Beltrán, "Respuesta política frente a las adversidades naturales en el sector agrícola durante el siglo XviII", en Revista de Historia Moderna, núm. 23, Alicante, 2005, 359-390. 
castigo del Altísimo por los hipotéticos pecados cometidos, el sentimiento popular cifraba sus esperanzas en la piedad divina, recurriendo para ello a la intermediación de santos y vírgenes y desarrollando las consabidas ceremonias específicas. De ahí que, en los peores momentos, se sucedieran misas, procesiones, rogativas, exposición del santísimo y de las imágenes de los más venerados patronos, se plantaran cruces "de langosta" a la entrada de los pueblos, florecieran los rituales de conjuro y exorcismo para preservar los campos y, en fin, se recurriera a determinadas reliquias como solución última para conjurar el mal. Entre ellas, y al margen de las devociones particulares existentes en cada localidad, lo cierto es que una sociedad tan sacralizada como lo era la española del siglo xviı tenía confianza ciega en los efectos benéficos del agua pasada por las cuencas de la calavera de San Gregorio Ostiense y, en tierras del Levante español, en los poderes taumatúrgicos de la Cruz de Caravaca. ${ }^{57}$

La devoción al primero, santo apócrifo por cierto, tiene su origen en una terrible plaga de langosta que asoló a comienzos del siglo XI las tierras de Navarra y La Rioja y que éste, según la leyenda, logró aniquilar a fuerza de ayuno y oración. ${ }^{58}$ Erigido, tras notable peripecia, un santuario en Sorlada para custodiar sus reliquias se adoptó la costumbre de hacer pasar agua a través de ellas para ahuyentar a los voraces insectos. Con el paso del tiempo muchas poblaciones espańolas optaron, en momentos en los que la langosta devoraba todo lo que encontraba a su paso, por enviar delegados para conseguir odres del preciado líquido con el que, una vez retornados a sus lugares de origen, se desarrollaba un ritual, próximo al exorcismo, consistente

${ }^{57} \mathrm{Al}$ respecto véanse todas las referencias bibliográficas contenidas en mi artículo "Procesiones, rogativas, conjuros y exorcismos...". Asimismo Pedro Ballester Roca, $\mathrm{La}$ cruz de Caravaca. Historia, rito y tradición, Murcia, 2001.

${ }^{58}$ Juan José Barragán Landa, "Las plagas del campo español y la devoción a San Gregorio Ostiense", en Cuadernos de Etnología y Etnografía de Navarra, núm. 29, 1978, 273-298. Roldán Jimeno Aranguren, El remedio sobrenatural contra las plagas agrícolas hispánicas. Estudio institucional y social de la cofradía y santuario de San Gregorio Ostiense (siglo XIII-XX), Cofradía de San Gregorio Ostiense-Gobierno de Navarra, Navarra, 2005; del mismo autor "San Gregorio Ostiense de Navarra. Abogado contra plagas agrícolas y males del oído", en Religiosidad popular en España. Actas del Simposium (I), 1/4-IX-1997, CIEIHA, Ediciones Escurialenses, San Lorenzo del Escorial, 1997, 309-356. 
FIGURA 2. Itinerario seguido por las reliquias de san Gregorio Ostiense durante 1756

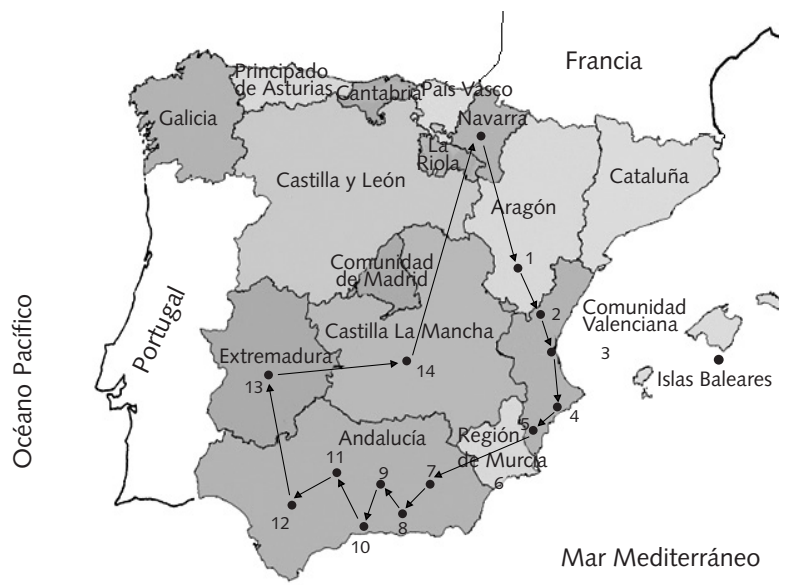

Claves: $1=$ ciudad de Teruel, $2=$ Diócesis de Segorbe, $3=$ D. de Valencia, $4=$ ciudad de Alicante; $5=$ Diócesis de Orihuela, 6= D. de Murcia, 7= D. de Guadix, 8= D. de Granada, 9= D. de Jaén, 10= D. de Málaga, 11= D. de Córdoba, 12=D. de Sevilla, 13= Provincia de Extremadura, 14= Provincia de La Mancha (Elaboración: C. Alberola Die).

en bendecir e hisopar los campos para preservarlos del flagelo de la plaga. A partir de año 1522, y en situaciones límite, se adquirió la práctica de transportar el relicario-cabeza de San Gregorio a los lugares amenazados. Durante el siglo XvII se produjeron dos salidas de alcance peninsular, una en 1634 y la otra en 1687-1689; pero, sin duda, la que mayor resonancia alcanzó fue la acaecida a mediados del siglo XVIII. Ya he apuntado páginas atrás que el rey Fernando VI, ante las enormes proporciones que alcanzó la plaga iniciada en 1754, determinó dos años más tarde que la cabeza del Ostiense recorriera el país para conjurar el grave peligro que se cernía sobre la agricultura. En carruaje, y conducida por tres cofrades eclesiásticos y uno secular, el viaje de la reliquia siguió un itinerario cuidadosamente establecido próximo a los 2,500 kilómetros (véase figura 2) que duró cuatro meses y que, salvo la expectación que levantó y los problemas de carácter institucional que pudieron plantearse, resultó poco efectivo. 
La plaga acabó cuando las condiciones medioambientales se tornaron desfavorables para que la langosta mantuviera la fase gregaria. Los recursos invertidos en la iniciativa, con cargo a la Hacienda real, resultaron importantes; como también lo fueron los derivados del desarrollo de las diferentes procesiones, rogativas, conjuros y exorcismos llevados a cabo por ciudades y villas afectadas contribuyendo, con ello, a su creciente endeudamiento. La realidad se mostraba, pues, en toda su crudeza al resultar ineficaces tanto los remedios terrenales como los espirituales, con el agravante de que los gastos, cada vez mayores, corrían siempre por cuenta de los mismos. La langosta, por tanto, siempre devoraba con fruición algo más que campos y sembrados.

\section{BibLIOGRAFÍA CITADA}

Abellán Pérez, Juan, "Las plagas de langosta en el valle del Segura durante la primera mitad del siglo Xv", Anales de la Universidad de Murcia, vol. 38, núm. 3, 1981, 81-94.

Aguilar Piñal, Francisco, Bibliografía de autores españoles del siglo XVIII, 10 vols., Madrid, CSIC, 1998-2001.

Alberola RomÁ, Armando "Procesiones, rogativas, conjuros y exorcismos. El campo valenciano ante la plaga de langosta de 1756", Revista de Historia Moderna, núm. 21, Universidad de Alicante, 2003, 383-410.

"No puedo sujetar la pluma de puro frío, porque son extremados los yelos. El clima en la España de los reinados de Felipe V y Fernando VI a través de la correspondencia de algunos ilustrados", en Investigaciones Geográficas, núm. 49, 2009, 65-88.

Catástrofe, economía y acción politica en la Valencia del siglo XVIII, Valencia, ediciones Alfonso el Magnánimo, 1999, 207235.

Quan la pluja no sap ploure. Sequeres i riuades al País Valencià en l'edat moderna, Valencia, Publicaciones de la Universidad de Valencia, 2010.

Alvar EzQuerra, Alfredo, "Castilla 1590: tres historias ejemplares", Studia Historica. Historia Moderna, núm. 17, Salamanca, 1997, 121-143. 
Aponte Marín, Ángel, “Conjuros y rogativas contra las plagas de langosta en Jaén (1670-1672)”, en Carlos Álvarez Santaló y otros, coords., La religiosidad popular. II: Vida y muerte: la imaginación religiosa, Barcelona, 1989, 554-562.

Arias Giralda, Antonio et al., La langosta mediterránea. Dociostarus maroccanus (Thunberg), Madrid, Ministerio de Agricultura, Pesca y Alimentación, 1994.

Asso y Del Río, Ignacio, Discurso sobre la langosta y medios de exterminarla. Por don-, Cónsul General de S. M. en Holanda, Ámsterdam, Sommer, MDCCLXXXV.

Azcárate Luxán, Isabel y Luis Maldonado Polo, "La plaga de la langosta y el tizón del trigo en la España ilustrada”, en Llull, vol. 15, 1992, 309-330.

Ballester Roca, Pedro, La cruz de Caravaca. Historia, rito y tradición, Murcia, 2001.

BArCeló, Miquel: "Les plagues de llagost a la Carpetània, 578649...", en Estudis d'Història Agraria, núm. 1, Barcelona, 1978, 67-84.

BARragÁn LANDA, Juan José: "Las plagas del campo español y la devoción a San Gregorio Ostiense", en Cuadernos de Etnología y Etnografía de Navarra, núm. 29, 1978, 273-298.

Benlloch, Miguel y José del CañIzo, “Observaciones biológicas sobre la langosta común (Dociostarus maroccanus Thunb.), recogidas en los ańos 1940 y 1941”, Boletín de Patología Vegetaly Entomología Agrícola, x, Madrid, 1941, 110-124.

Benlloch, Miguel: "Influencia de la humedad y la temperatura sobre la vitalidad y desarrollo de los huevos de langosta", Boletín de Patología Vegetal y Entomología Agrícola, x, Madrid, 1947, 271-274.

Bowles, Guillermo, Historia natural de la langosta en España y modo de destruirla, por don Guillermo Bowles..., Madrid, Imprenta de D. M. de Burgos, 1825.

Introducción a la Historia Natural y a la geografía física de España, por-. En Madrid, imprenta de D. Francisco Manuel de Mena, 1775 (Segunda edición, corregida. En Madrid, en la Imprenta Real, año de 1782). 
Brito GonzÁlez, Oswaldo, "La langosta en Canarias durante el Antiguo Régimen", en Anuario de Estudios Atlánticos, núm. 35, 1989, 67-102.

Buj Buj, Antonio: "Control de las plagas de langosta y modernización agrícola en la España de la segunda mitad del siglo XIX", en Geocrítica. Cuadernos Críticos de Geografía Humana, núm. 95, Barcelona, julio 1992 [trabajo consultable igualmente en Scripta Vetera. Edición electrónica de trabajos publicados sobre Geografía y Ciencias Sociales, www.ub.es/geocrit/sv-59.htm].

Calvo García-Tornel, Francisco, "Le risque comme paradoxe et comme défi", en Gérard Chastagnaret, Les sociétés méditerranéennes face au risque. Disciplines, temps, espaces, El Cairo, Institut Français d'Archéologie Orientale, 2008, 165-178.

El riesgo. Un intento de valoración geográfica, Murcia, Academia Alfonso X “el Sabio", 1982.

Catalá i Roca, Pere, La plaga de llagosta a Catalunya, 1686-1688, Barcelona, R. Dalmau editor, 1987.

Cózar Gutiérrez, Ramón, "La administración municipal y el control de las plagas de langosta en Albacete a principios del siglo xviI", Ensayos. Revista de la E.U. de Magisterio de Albacete, núm. 18, Albacete, 2003, 47-60.

Del Cañızo Gómez, José, "La langosta y el clima", Boletín de Patología Vegetal y Entomología Agrícola, XI, Madrid, 1942, 179-200.

Del Cañizo, José y Víctor Moreno, "Ideas actuales sobre las plagas de langosta”, Boletin de Patologia Vegetal y Entomología Agrícola, IX, Madrid, 1940, 107-136.

Díaz-Pintado, Juan, "Climatología de La Mancha durante el siglo xvin", en Cuadernos de Historia Moderna, núm. 12, Madrid, 1991, 123-166.

García Herrero, María del Carmen y María de Jesús TorreblanCA GASPAR, "San Miguel y la plaga de langosta (Claves para la interpretación del voto taustano de 1421)", Aragón en la Edad Media, X-XI. Homenaje a la profesora $M^{a}$ Luisa Ledesma Rubio, Universidad de Zaragoza, 1993, 281-305.

GonzÁlez Beltrán, Jesús Manuel, "Respuesta política frente a las adversidades naturales en el sector agrícola durante el siglo 
xviII", en Revista de Historia Moderna, núm. 23, Alicante, 2005, 359-390.

IzQuierdo BEnito, Ricardo, "Las plagas de langosta en Toledo y la región manchega durante el siglo XVI", en Anales Toledanos, Toledo, 1985, 47-143.

Jimeno Aranguren, Roldán: "San Gregorio Ostiense de Navarra. Abogado contra plagas agrícolas y males del oído”, en Religiosidad popular en España. Actas del Simposium (I), 1/4-IX-1997, CIEIHA, Ediciones Escurialenses, San Lorenzo del Escorial, 1997, 309-356.

El remedio sobrenatural contra las plagas agricolas hispánicas. Estudio institucional y social de la cofradia y santuario de San Gregorio Ostiense (siglo XIII-XX), Cofradía de San Gregorio OstienseGobierno de Navarra, Navarra, 2005.

LEÓN VALDÉs, Milagros, "Una simiente devastadora del agro antequerano: la plaga de langosta de 1620", Revista de Historia Moderna, núm. 23, número monográfico dedicado a Agricultura, riesgos naturales y crisis en la España moderna, Alicante, 2005, 285-306.

López Cordero, Juan Antonio y Aponte Marín, Ángel, Un terror sobre Jaén: las plagas de langosta (siglos XVI-XIX), Jaén, 1993.

Marín López, Rafael, "Noticias de una plaga de langosta en Granada en 1670-1671", Actas del VII Congreso de Profesores-Investigadores. Hespérides, Motril, 1988, 245-247.

Meseguer Fernández, Juan, "Plaga de langosta en el marquesado de Villena y Castilla la Nueva, el año 1549”, Al-Basit, núm. 6, Albacete, 1979, 61-69.

Montemayor, Julián, "Les invasions de sauterelles dans l'Espagne intérieure”, en Bartolomé Bennassar, ed., Les catastrophes naturelles dans l'Europe médievale et moderne, Toulouse, Presses Universitaires du Mirail, 1996, 261-269.

PÉrez Moreda, Vicente, Las crisis de mortalidad en la España interior (siglos XVI-XIX), Madrid, Siglo XXI editores, 1980.

Peris Felipo, Javier, "Apuntes sobre la lucha contra la plaga de langosta en los escritos de los siglos modernos", en Tiempos Modernos. Revista Electrónica de Historia Moderna, núm. 17, 2008/2. 
Piqueras García, María Belén, "Una amenaza para la agricultura de Almansa: las plagas de langosta (1756-1759), en Al-Basit, núm. 23, Albacete, 1988, 189-201.

QuiÑones, Juan, Tratado de las langostas muy utily necesario, en que se tratan cosas de provecho i curiosidad para todos los que professan letras divinas i humanas i las mayores ciencias. Compuesto por el doctor-..., En Madrid, por Luis Sánchez impresor del Rey nuestro Señor, año de MDCXX.

Rodríguez Molina, José, "Los insecticidas en la etapa pre-científica”, Boletín del Instituto de Estudios Giennenses, núm. 153, xL, 1994, 685-743.

Rubio Vela, Agustín, "Presencia de la langosta. Plagas en la Valencia Bajomedieval”, Saitabi, núm. 47, Valencia, 1997, 269-288.

Salido y Estrada, Agustín, La langosta. Compendio de todo cuanto más notable se ha escrito sobre la plaga, naturaleza, vida e instintos de este insecto..., Madrid, Imprenta, Fundición y Estereotipia de don Juan Aguada, 1874.

Sistach, Xavier, Bandas, enjambres y devastación. Las plagas de langosta a través del la historia, Almuzara, 2007.

Tarifa Fernández, Adela y Antonio Linaje Conde, "Úbeda, 1680-1713. Cambio dinástico y coyuntura económica”; Homenaje a don Antonio Dominguez Ortiz, vol. II, Granada, 2008, 757-770.

Tarifa Fernández, Adela, Manuel Morales Romero y Enrique García García, "La ciudad de Úbeda a principios del siglo xviII: la plaga de langosta de 1709", Actas del x Congreso de Profesores-Investigadores. Hespérides, Sanlúcar de Barrameda, 1991, 299-308.

Torres Fontes, Juan, "Los enemigos del hombre”, Murgetana, LXI, 1981.

Uvarov, Boris P., "Ecology of the Moroccan locust in Iraq and Syria and the prevention of its outbreaks", Bulletin of Entomological Research, xxIV, 1, 1934, 407-418.

$\longrightarrow$ Locusts and grasshoppers, Londres, The Imperial Bureau of Entomology, 1928.

, "Ecological studies of the Moroccan locust in Western Ana- 
tolia”, Bulletin of Entomological Research, xxiII, 2, 1932, 273287.

VÁzquez Lesmes, Rafael y Cándido Santiago Vázquez, Las plagas de langosta en Córdoba, Córdoba, Cajasur, 1993.

Villalba, Joaquín de, Epidemiología española o historia cronológica de las pestes, contagios, epidemias y epizootias que han acaecido en España..., 2 vols., Madrid, 1803.

Ximénez Patón, Bartolomé, Discurso de la langosta que en el tiempo presente aflige, y para el venidero amenaza, por D. -. Baeza, 1619. Zepeda y Vivero, Juan Antonio, Agricultura metódica, acomodada a la práctica del pais, con varias noticias acerca de la naturaleza, propagación y extinción de la langosta. Escrita por don-. Cura rector del lugar de Malpartida de Plasencia. En Madrid, en la Oficina de don Benito Cano, año de MDCCXCI.

FeCha de RECEPCión DEL ARTículo: 23 de junio de 2011

FECHA DE ACEPTACIÓN Y RECEPCIÓN DE LA VERSIÓN FINAL: 19 de julio de 2011 